\title{
IMPORTÂNCIA DA FIBRA NA NUTRIÇÃO DE COELHOS
}

\author{
IMPORTANCE OF FIBRE IN RABBIT NUTRITION
}

\author{
Alexandra del Pilar Naranjo Herrera ${ }^{1}$ Genário Sobreira Santiago ${ }^{2}$ \\ Silvana Lúcia dos Santos Medeiros ${ }^{3}$
}

\section{REVISÃO BIBLIOGRÁFICA}

\section{RESUMO}

\begin{abstract}
Os coelhos, por serem herbívoros não ruminantes, podem ser alimentados com considerável quantidade de alimentos fibrosos. No entanto, não apresentam eficiência tão grande para utilizar essa fibra sendo, nesse aspecto, inferior aos ruminantes e, inclusive, aos suínos. Por outro lado, a fibra, apesar de seu escasso valor nutritivo, apresenta valor lastre, sendo importante, pois, na regulação do trânsito da digesta e na prevenção de distúrbios digestivos. Assim, o objetivo deste artigo é revisar alguns aspectos da composição química da fibra e de sua digestão pelos coelhos, bem como a sua relação com outros nutrientes da dieta, como proteína e energia.
\end{abstract}

Palavras-chave: digestão, energia, proteína, amido.

\section{SUMMARY}

Rabbits are monogastric herbivorous that intake quantity significative of fibrous feed. However they not show efficiency to degrate this fibre, being less capacity, in this aspect that ruminants and inclusively, of the swine. For other hand, the fibre have ballast value, being important in the transit digestive regulation and prevention of digestive disturb. Thus, the objetive of this paper is to review some aspects of chemistry composition of fibre and it's digestion for rabbits and it's relation with other components of diet like protein and energy.

Key words: digestion, energy, protein, amido.

\section{INTRODUÇÃO}

O coelho apresenta capacidade de se alimentar com considerável quantidade de produtos fibrosos, no entanto, é um animal pouco eficiente no uso da fibra como fonte de energia, sendo inferior, neste aspecto, aos ruminantes e aos eqüinos e, inclusive, aos suínos. Essas diferenças podem ser atribuídas mais ao conteúdo em complexos lignocelulósicos, que ao próprio teor de fibra da dieta. (GARCIA, 1997). A importância da fibra na nutrição dos coelhos não se limita, apenas, ao seu valor como suplemento nutritivo, mas também se relaciona com a regulação do trânsito da digesta e com a manutenção da integridade da mucosa intestinal (De BLAS et al., 1999). Assim, o papel da fibra parece ser o de estimular e facilitar o trânsito digestivo dos alimentos, principalmente por sua fração indigestível, papel que não pode ser substituído, satisfatoriamente, por substâncias inertes (De BLAS, 1992).

A celulose estimula o trânsito digestivo e a motilidade intestinal. Aportes de fibra bruta (FB) inferiores a 6\%, segundo DAVIDSON \& SPREADBURY (1975) citados por FRAGA et al. (1984) e a $12 \%$, segundo LEBAS (1975), determinam alterações digestivas caracterizadas por fermentação tóxica com proliferação de microrganismos anaeróbios de putrefação, que estão associados a fatores de estresse do ambiente ou da própria alimentação, produzindo enterites, diminuição do crescimento e mortalidade. Este artigo tem como objetivo revisar a importância da fibra na nutrição de coelhos, abordando alguns aspectos inerentes a sua

\footnotetext{
${ }^{1}$ Médico Veterinário e Zootecnista, Doutorando em Zootecnia, Escola de Veterinária, Universidade Federal de Minas Gerais (UFMG), Colegiado de Pós-graduação. Avenida Antônio Carlos 6627 CP 567, 30161-970, Belo Horizonte, MG. E-mail: alexanaranjo@yahoo.com. Autor para correspondência.

${ }^{2}$ Médico Veterinário, Professor Adjunto de Bioquímica Veterinária da Faculdade de Veterinária da UECE, Doutorando em Ciência Animal, EV/UFMG.

${ }^{3}$ Médico Veterinário, Doutorando em Ciência Animal, EV/UFMG. 
composição química, bem como as interações da fibra com outros nutrientes da dieta como energia e proteína.

\section{PAPEL DA FIBRA NA NUTRIÇÃO DO COELHO}

\section{Influência do teor de fibra da dieta}

O fato do coelho possuir o aparelho digestivo desenvolvido (principalmente o ceco) e a existência neste de uma flora microbiana ativa resultam em uma capacidade relativamente alta, se comparada aos suínos e às aves, em aproveitar os alimentos grosseiros. Essa capacidade, entretanto, não se equipara à dos ruminantes (CHEEKE, 1983). Os trabalhos desenvolvidos por De BLAS et al. (1985) demostraram que a fibra é necessária para facilitar o trabalho mecânico do tubo digestivo e que, geralmente, os coelhos devem receber entre 12 a $17 \%$ de FB em suas dietas. De acordo com HOOVER \& HEITMANN (1972), conteúdo de FB da dieta não deve ser menor que 8 a $10 \%$, pois quantidades inferiores reduzem o peristaltismo intestinal, provocando diarréias. BORIELLO \& CARMAN (1983) demostraram que o conteúdo de fibra da dieta está diretamente relacionado com problemas digestivos no coelho. Assim, para se conseguir desempenho satisfatório dos animais, sem risco de diarréias, as dietas devem conter 13 a $14 \%$ de FB. CHEEKE \& PATTON (1980) relataram que teores elevados de fibra na dieta evitaram a enterotoxemia e combateram enterites em coelhos, sendo que os teores recomendados estão entre 15 e $20 \%$ de FB. As considerações anteriores sugerem que enterite mucóide e diarréia podem ser controladas pela adição de material fibroso na ração, para que seja mantida a normalidade do trânsito digestivo. Ainda sob esse aspecto, tem sido sugerido (LEBAS \& LAPLACE, 1977) que a hipomotilidade do aparelho digestivo pode ser a causa inicial das diarréias. Com relação a essa teoria, as dietas com alto conteúdo em fibra não digestível relacionam-se com baixos teores de ácido butírico no ceco, ocasionando maior velocidade de trânsito digestivo. Pelo contrário, dietas com baixo teor de fibra permanecem demasiado tempo no ceco, dando lugar a fermentações indesejáveis.

Outra teoria sobre a origem das diarréias, referente ainda ao conteúdo baixo em fibra, está relacionada à elevada concentração de amido. Se a capacidade de digerir o amido, por parte das amilases, é limitada, quantidades elevadas de amido podem passar ao ceco, produzindo maior quantidade de ácidos graxos voláteis (AGV), favorecendo o crescimento de bactérias indesejáveis, resultando no aparecimento de diarréias (PROHASKA, 1980 citado por De BLAS, 1992).

\section{A fibra com fonte de energia}

Com quantidades variando entre 18 e $24 \%$ de fibra em detergente ácido (FDA), os coelhos em crescimento podem regular a ingestão de energia e seu crescimento não varia significativamente (De BLAS et al., 1989). A energia digestível (ED) é expressão do valor energético na elaboração de dietas para coelhos. Variações na quantidade de fibra entre 11,8 a $30,9 \%$ ingerida diariamente poderiam ter efeitos negativos sobre o processo de fermentação no ceco, como a ocorrência de diarréia e, conseqüentemente, na eficiência de utilização da ED. Trabalhos de De BLAS et al. (1985), usando dietas com conteúdo de 8 até $16 \%$ de FDA indicaram incremento significativo no ganho de peso para maior valor de FDA. O conteúdo de fibra tem efeito negativo sobre a digestibilidade da energia bruta (EB), sendo que isso não significa que a fibra tenha um valor negativo em energia, mas sim um menor conteúdo de energia que os outros componentes da dieta (De BLAS et al., 1999).

A digestibilidade da fibra de um ingrediente pode estimar-se pelo método diferencial com substituição de uma dieta basal, indicando, a primeira vista, importante variabilidade de 7 a $72 \%$ de digestibilidade entre os alimentos. Baixa digestibilidade foi encontrada para forragens e bagaço da uva. A digestibilidade da fibra para concentrados protéicos apresentou valores intermediários, sendo mais altos para o farelo de soja que para o farelo de girassol. Finalmente, pouca lignificação, como em produtos como beterraba e polpa cítrica, resulta em altos valores de digestibilidade da fração fibrosa (GIDENNE, 1993; GARCIA, 1997).

Outra consideração a ter-se em conta é a heterogeneidade dos diferentes componentes da parede celular. Como consequiência destas diferenças no grau de lignificação, e também da elevada digestibilidade das pectinas, a substituição destes ingredientes na dieta determina elevadas e significativas diferenças da ED na dieta. Na tabela 1, encontram-se dados de ED e FDA de alguns produtos altamente lignificados e utilizados na dieta de coelhos.

Além disso, as diferenças paralelas no peso do conteúdo do ceco apresentam correlação positiva entre o volume do ceco e a degradação da fibra, porque o maior desenvolvimento do ceco, observado com a dieta à base de polpa, deve-se à ocorrência de um estímulo químico mais intenso no referido órgão, pois a polpa tem uma fermentabilidade superior àquela dos ingredientes mais fibrosos 
Tabela 1 - Composição química percentual e valor energético de ingredientes em base MS (Matéria Seca).

\begin{tabular}{lrrc}
\hline Ingrediente & FDA & FDN & $\mathrm{ED}\left(\mathrm{Mjkg}^{-1}\right)$ \\
\hline Milho & 4,2 & 14,5 & 15,6 \\
Trigo & 6,7 & 23,1 & 14,9 \\
Bagaço de uva & 54,3 & 61,7 & 5,8 \\
Feno alfafa & 31,8 & 49,9 & 9,1 \\
Polpa de beterraba & 24,0 & 45,0 & 13,7 \\
Palha & 51,5 & 79,5 & 1,2 \\
\hline
\end{tabular}

Fonte: FERNÁNDEZ-CARMONA et al. (1996).

ou lignificados como o feno de alfafa, além do que o conteúdo do sistema digestivo está relacionado com a excreção e ingestão de cecotrofos, bem como com o consumo de alimento e excreção de fezes duras. FERREIRA (1990), ao substituir a alfafa por polpa de beterraba, detectou diferença significativa no peso do sistema digestivo repleto, sendo que o maior valor $(486,5 \mathrm{~g})$ foi observado na dieta em que a alfafa foi substituída pela polpa em $40 \%$. No mesmo trabalho, o autor verificou que a substituição de alfafa em $20 \%$ pelo bagaço de uva levou a uma diminuição significativa do peso do sistema digestivo repleto $(409,2 \mathrm{~g})$, no entanto o autor não observou efeito significativo para o peso do sistema digestivo vazio em ambas as dietas. O esquema de Van Soest permite corrigir parte, mas não todas, dessas diferenças. Para dietas que contenham polpa de beterraba ou polpa cítrica há relação diretamente proporcional da ED com o teor de FDA. No entanto, inclusão superior a $15 \%$ resulta em diminuição do crescimento e da eficiência de conversão da ED para crescimento (GARCIA et al., 1997).

\section{Efeito da relação fibra / amido}

Baixo teor de fibra dietética, sem grandes mudanças na proporção dos constituintes da parede celular, não afeta significativamente o peso do conteúdo cecal, mas altera sua composição (CARABAÑO et al., 1989). O teor de fibra do ceco decresce, como ocorre com o de proteína, quando a concentração de amido permanece baixa, perto de $1,5 \%$ (FRAGA et al., 1984). Baixa quantidade de fibra dietética poderia também modificar a mucosa cecal e causar deterioração das vilosidades do colo (YU \& CHIOU, 1996). Muitos autores não observaram mudanças significativas nos produtos finais da fermentação como amônia (NH3), AGV, e $\mathrm{pH}$ cecal em resposta ao decréscimo na ingestão de fibra (HOOVER \& HEITMANN, 1972; CARABAÑO $\boldsymbol{e}$ t $\boldsymbol{a l}$., 1988; MORISSE $\boldsymbol{e t}$ al., 1993; GARCIA et al., 1997; BELLIER \& GIDENNE, 1996), mas a proporção molar de AGV é afetada pelo nível de fibra (LUICK et al., 1992).
A digestibilidade da fibra não é afetada pelo seu conteúdo, porém a quantidade de fibra degradada é diminuída (combinação de baixa ingestão de alimento e baixo teor dietético de fibra) (De BLAS, 1992). A quantidade de fibra que alcança o ceco não é um fator limitante para o processo de fermentação, provavelmente porque o tempo de retenção da digesta no ceco é relativamente curto, permitindo, principalmente, a degradação da fração facilmente digestível, tais como pectinas e hemiceluloses (GIDENNE, 1994). Além disso, o tempo de retenção no ceco aumenta proporcionalmente à redução da ingestão de fibra (GIDENNE, 1996) e poderia, então, compensar eventual limitação da fibra que entra no ceco. Entretanto, para teor de fibra muito baixo (FDA < 10\%), algum aumento na eficiência de degradação da fibra foi notado e poderia ser atribuído ao prolongado tempo de retenção no segmento ceco-cólico (De BLAS et al.,1988; BELLIER \& GIDENNE, 1996). A quantidade de fibra que entra no ceco parece não ter influência no suprimento energético para a fermentação cecal. Entretanto, GIDENNE (1994) alerta para o fato de que esses resultados foram obtidos com coelhos adultos, alimentados com dietas semipurificadas.

\section{Inter-relação proteína e fibra}

Em trabalhos realizados com coelhos de raça Nova Zelândia Branca, FRAGA et al. (1984) obtiveram crescimento máximo para o peso no abate $(2,300 \mathrm{~g})$ de animais que receberam dietas contendo 13 a $14 \%$ de PB e $7 \%$ de FB. No entanto, esses resultados diferiram daqueles de PEREZ et al. (1996) que obtiveram maiores ganhos de peso $(29,43 \mathrm{~g} / \mathrm{dia})$ usando dieta com $7 \%$ de FB e $11 \%$ de PB. Segundo Bonatti (1979), apud VILLAMIDE \& De BLAS (1991), o desempenho de coelhos, nas fases de crescimento e engorda, está associada ao teor de proteína da dieta (15 a 18\% PB), sendo que estas dietas devem conter no mínimo $12 \%$ de FB. De acordo com as observações de Cabrero (1979) apud De BLAS $\boldsymbol{e t}$ al. (1985), os coelhos, a partir de 30 dias de vida até a idade de abate, necessitam de $16 \%$ de PB e 13 a $14 \%$ de FB em suas dietas. Os autores sugerem que teores maiores de proteína e menores de fibra que os propostos acarretam riscos elevados de diarréia. Utilizando coelhos em crescimento (30 dias), alimentados com dietas contendo 12, 14, 16 e 18\% de PB e 7, 11 e $15 \%$ de FB, Echagüe (1979) apud De BLAS et al. (1988), observou que para manter constante a velocidade de crescimento ( $23 \mathrm{~g} / \mathrm{dia})$, é necessário variar o nível de proteína da dieta em função do nível de fibra, de maneira a se obter relação de $23,5 \mathrm{kcal}$ de ED/g de proteína digestível (PD). A eficiente utilização da proteína foi deprimida 
conforme se incrementava, paralelamente, o nível de proteína da dieta (DEHALLE, 1981). A elevação do teor de fibra na dieta, qualquer que seja este, não incrementa a quantidade de proteína exigida para ganhar $1 \mathrm{~kg}$ de peso (NOMANI \& STANSBERRY, 1982). Não foi observada relação significativa entre digestibilidade da proteína e teor de FB. Aumentos de 7 a $13 \%$ da FB não diminuíram a digestibilidade aparente da PB (FEKETE \& GIPPERT, 1985). O nível de fibra na dieta não parece afetar o coeficiente de digestibilidade da PB. Este parâmetro depende, em maior medida, da origem da proteína, que sofre variações entre os diferentes trabalhos (FRAGA $\boldsymbol{e t}$ al. 1984). Dietas com teores de FDA entre 9 e 24\% apresentaram diminuição de 0,74 pontos percentuais no coeficiente de digestibilidade da PB ao se aumentar $1 \%$ o teor de FDA da dieta (valores de PB e FDA variam paralelamente) (CARABAÑO et al., 1988).

\section{Papel da fibra na prevenção de distúrbios digestivos}

Algumas relações entre nutrição e aumento de distúrbios digestivos observaram-se em trabalhos ïn vitro de alguns autores (PROHASZKA, 1980 citado por De BLAS, 1992; BORRIELLO \& CARMAN, 1983). Esses estudos sugeriram possível relação entre o tipo de dieta e a maior frequiência de diarréias. Aporte de FB inferior a 6\%, segundo Davidson \& Spreadbury (1975), apud FRAGA et al. (1984), determina alterações digestivas, com fermentações tóxicas e proliferação de microrganismo de putrefação, que produzem enterites. Dietas altamente fibrosas $(21 \% \mathrm{FB})$, com alta proporção de amido de trigo (30\%), aumentam significativamente $\mathrm{o}$ pH no ceco, provocando decréscimo significativo das concentrações de AGV, propiciando as condições para promover proliferação de $\boldsymbol{E}$. coli (Prohaszka, 1980, apud De BLAS, 1992; WALLACE et al., 1989).

Outro fato que deve ser levado em consideração é o tipo de fibra a ser usada na dieta, quando se trata de fermentação do ceco em relação à suacomposição. A inclusão de produtos altamente lignificados à dieta, como por exemplo resíduo de uva, implica leve aumento do $\mathrm{pH}$ do ceco, que é reduzido quando se inclui polpa de beterraba à dieta. Efeitos opostos observam-se quando da substituição do feno de alfafa por bagaço de uva e polpa de beterraba, refletindo-se sobre as concentrações significativas, ou não de $\mathrm{AGV}$ e $\mathrm{NH}_{3}$ no ceco, sendo que o menor valor foi de $31,8 \mathrm{mMo} \ell / \ell$, obtido com o nível máximo de substituição $(60 \%)$ comparado com concentrações normais que oscilaram entre 40 a 65

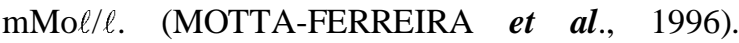

Independentemente do tipo de microflora existente no ceco, é mais degradada a fração solúvel da parede celular (pectinas, pentosas, $\beta$-glucanos, oligossacarídeos) (MAROUNECK et al., 1995). Esses resultados sugerem possível interesse em combinar diferentes fontes de fibra ajustando-se as frações digestível e indigestível.

\section{CONCLUSÕES}

A fibra na nutrição de coelhos é muito importante por todos os aspectos mencionados, devendo estar entre 18 a $24 \%$ de FDA, por ser melhor estimador da ED. A fonte de energia depende do tipo de fibra utilizado na dieta; assim, fibras pouco lignificadas apresentam altos valores de digestibilidade com redução dos valores de ED. A inclusão de teores médios a elevados de fibra não digestível na dieta produz redução da densidade energética que pode ocasionar problemas em coelhos que possuem necessidades maiores. A fibra estimula e facilita o trânsito digestivo dos alimentos, principalmente por sua fração indigestível evitando, dessa forma, a proliferação de bactérias patogênicas e surgimento de enterites.

Os trabalhos revisados sugerem não haver clara relação entre os teores dietéticos de fibra e a digestibilidade aparente da PB. A principal medida nutricional parece ser a combinação de diferentes fontes de fibra na dieta de coelhos, aproveitando vantagens, e desvantagens, dos dois tipos de fibra (digestível e indigestível), evitando-se problemas digestivos e desbalance das dietas.

\section{REFERÊNCIAS BIBLIOGRÁFICAS}

BELLIER, R., GIDENNE, T. Consequence of reduced fibre intake on digestion, rate of passage and caecal microbial activity in the young rabbit. British Journal of Nutrition, v.75, n.2, p.353-363, 1996.

BORIELLO, S.P., CARMAN, R.J. Association of iota-like toxin and Clostridium spiriforme with both spontaneous and antibiotic-associated diarrhoea and colitis in rabbits. Journal Clinical Microbiology, v.17, n.2, p.414-418, 1983.

CARABAÑO, T., FRAGA, M.J., SANTOMÁ, G. et al. Effect of diet on composition of caecal contents and on excretion and composition of soft and hard feces or rabbits. Journal of Animal Science, v.66, n.4, p.901-910, 1988

CARABAÑO, R., FRAGA, M.J., De BLAS, J.C. Effect of protein source in fibrous diets on performance an digestive parameters of fattening rabbits. Journal Applied of Rabbit Research, v.12, n.3, p.201-204, 1989.

CHEEKE, P.R., PATTON, N.M. Carbohydrate overload of the hindgut; a probable cause of enteritis. Journal Applied of Rabbit Research, v.3, n.3, p.20-23, 1980. 
CHEEKE, P.R. The significance of fibre in rabbit nutrition. Journal Applied of Rabbit Research, v.6, n.3, p.103-106, 1983.

De BLAS, J.C., FRAG, M.J., CARABAÑO, R. et al. Units for feed evaluation and requirements for comercially growth rabbits. Journal of Animal Science, v.60, n.4, p.1021-1027, 1985.

De BLAS, J.C., SANTOMÁ, G., CARABAÑO, R. Fibre and starch levels in fattening rabbits diets. Journal of Animal Science, v.63, n.6, p.1897-1904, 1988.

De BLAS, J.C., VILLAMIDE, M.J., CARABAÑO, R. Nutritive value of cereal by-products for rabbits. Journal Applied of Rabbit Research, v.12, n.3, p.148-151, 1989.

De BLAS, J.C. The roles or fibre in rabbit nutrition. Journal Applied of Rabbit Research, v.15, n.2, p.1329-1343, 1992.

De BLAS, J.C., GARCIA, J., CARABAÑO, R. Role of fibre in rabbit diets; a review. Annales Zootechnie, v.48, n.1, p.3$13,1999$.

DEHALLE, C. Equilibre entre les apports azotés et énergétiques dans lálimentatio du lapin en croissance. Annales Zootechnie, v.30, n.2, p.197-208, 1981 .

FEKETE, S., GIPPERT, T. Effect of crude fibre on protein utilization by rabbits. Journal Applied of Rabbit Research, v.8, n.1, p.31-38, 1985

FERNANDEZ-CARMONA, J. CERVERA, C., BLAS, E. Prediction of the enrgy value of rabbit feeds varying widely in fibre content. Animal Feed Science and Technology, v.64, p.61-75, 1996.

FERREIRA, W. Efecto de la sustitución parcial de heno de alfalfa por orujo de uva o pulpa de remolacha sobre utilización de la dieta y los rendimientos productivos en conejos en crecimiento. Madrid, 1990. 251p. Tesis. (Doutorado) - Universidad Politécnica de Madrid, 1990.

FRAGA, M.J., BARREÑO, C., CARABAÑO, R. et al. Efecto de los niveles de fibra y proteína del pienso sobre la velocidad de crecimiento y los parámetros digestivos del conejo. Annales Instituto Nacional de Investigación Agraria Serie Ganadera. v.21, p.91-110, 1984.

GARCIA, J. Estudio de distintas fuentes de fibra en la alimentación del conejo. Madrid, 1997. 310p. Tesis (Doutorado) - Universidad Politécnica de Madrid, 1997.

GIDENNE, T. Measurement of the rate of passage in testrictedfed rabbits: effect of dietary cell wall level on the transit of fibre particles of diferent sizes. Animal Feed Science and Technology, v.42, n.1/2, p.151-163, 1993.

GIDENNE, T. Effects d'une réduction de la teneur en fibres alimentaires sur le transit digestif du lapin. Comparaison et validation de modéles d'ajustement des cinétiques d'excrétion fécale des maqueurs. Reproduction Nutrition and Development, v.34, n.4, p.295-306, 1994.

GIDENNE, T. Aportes de fibra y almidón para los gazapos de engorde. Cunicultura, v.21, n.120, p.88-93, 1996.

HOOVER, W.H., HEITMANN, R.N. Effects of dietary fibre levels on weight gain, caecal volume and volatile fatty acid production in rabbits. Journal of Nutrition, v.31, n.102, p.375-379, 1972 .

LEBAS, F. Influence de la teneur en énergie de l'aliment sur les performances de croissance chez le lapin Annales Zootechnie, v.24, n.2, p.281-288, 1975.

LEBAS, F., LAPLACE, J.P. Le transit digestif chez le lapin. VII.- Influence de la finesse du broyage des constituants d'un aliment granulé. Annales Zootechnie, v.26, n.3, p.413-420, 1977.

LUICK, V.R., EL-SAYAAD, G.A., CHEEKE, P.R. Effect of fructo-oligosaccharides and yeast culture on growth performance of rabbits. Jorunal Applied of Rabbit Research, v.15, n.2, p.1121-1128, 1992.

MAROUNEK, M., VOVK, S.J., SKRIVANOVA, V. Distribution of activity of hydrolytic enzymes in the digestive tract of rabbits. British Journal of Nutrition, v.73, n.3, p.463-469, 1995.

MORISSE, J.P., MAURICE, R., BROILLETOT, E., et al. Assessmet of the activity of fruto-oligosaccharides on different caecal parameters in rabbits experimentally infected with $\boldsymbol{E}$. coli 0103. Annales Zootechnie, v.42, n.1, p.81-87, 1993.

MOTTA-FERREIRA, W., FRAGA, M.J., CARABAÑO, R. Inclusions of grape pomace, in substitution for alfalfa hay, in diets for growing rabbits. Animal Science, v.63, n.1, p.167174, 1996.

NOMANI, M.Z., STANSBERRY, S.C. Effect of dietary fibre fractions on the apparent digestibility of nitrogen and protein efficiency ratio in rats on two feeding plans. Nutrition and Reprodution International, v.26, p.695-702, 1982.

PEREZ, J.M. GIDENNE, T., BOUVAREL, I., et al. Apports de cellulose dans l'alimentation du lapin en croissance: II Conséquences sur les performances et la mortalité. Annales Zootechnie, v.45, n.4, p.299-309, 1996.

VILLAMIDE, M.J., De BLAS, J.C. Effect of type of basal diet and rate of inclusion on the evaluation of protein concentrates with rabbits. Animal Production, v.52, n.1, p.215-224, 1991.

WALLACE, R.J., FALCONER, M.L., BHARGAVA, P.K. Toxity of volatile fatty acids at rumen $\mathrm{pH}$ prevents enrichment of Escherichia coli by sorbitol in rumen contents. Current Microbiology, v.19, p.277-281, 1989.

YU, V., CHIOU,P.W.S. Effects of crude fibre level in the diet on the intestinal morphology of growing rabbits. Laboratory Animal, v.30, n.2, p.143-148, 1996.

Ciência Rural, v. 31, n. 3, 2001. 